\title{
A Comparative Analysis of Residents 'Satisfaction with People's Livelihood in Tourism Town of Yangshuo, Guangxi in the Decade
}

\author{
Su Zhen \\ Business School of Guangxi University \\ Nan Ning, China \\ 35943@163.com
}

\author{
Ren Chuanyang \\ Business School of Guangxi University \\ Nan Ning, China \\ 743521784@qq.com
}

\author{
Shi Huike \\ Business School of Guangxi University \\ Nan Ning, China \\ 972917910@qq.com
}

\begin{abstract}
It is helpful to measure the social impact of the tourism industry by investigating the changes of the residents' satisfaction with people's livelihood in tourism towns. Based on the descriptive statistical analysis and cross analysis of questionnaire survey data in Yangshuo County of Guilin, this paper discusses the changes of residents' satisfaction with people's livelihood over the past $\mathbf{1 0}$ years. It is found that the development of tourism industry has improved the overall satisfaction of people's livelihood in the past decade, but the price and the cost of living have experienced a certain degree of regression; and people's satisfaction with tourism livelihood differs in different groups. The above conclusions remind those small towns with tourism as the pillar industry to take into account the people's livelihood consideration in the process of tourism development.
\end{abstract}

Keywords-Tourism Destination, Residents, People's Livelihood, Satisfaction, Yangshuo, Guangxi

\section{INTRODUCTION}

People's livelihood refers to the basic survival and living conditions of the people. In tourism towns where the tourism industry and local social life are highly integrated, the satisfaction of local residents with livelihood would truthfully reflect the improvements of livelihood brought by the development of tourism industry in the region. Therefore, it is of great value and significance to study on people's satisfaction with livelihood in tourism towns in implementing specific social benefiting policies to increase the welfare of the people in the future.

In researches themed on tourism livelihood, the word "welfare" is mostly used to reflect the meaning of "people's livelihood" to study on the relationship between tourism and welfare or the relationship between tourism and the residents' quality of life. Research shows that the local economic development level, tourism scale and the uneven distribution of income could have an important impact on tourism welfare [1].
On the positive side, the impact is reflected when the development of tourism helps to expand the employment of local residents to a certain extent, and improve the level of welfare [2], besides, it can also be used as a driving force to promote the residents to obtain a happy life and welfare. For example, tourism has a positive impact on the welfare of local residents in Meghalaya, especially for women engaged in hotels and other tourism industries [4]. On the negative side, the main manifestation of the impact is that a series of problems in political, economic, cultural and environmental field brought by the development process of tourism decrease the welfare of local people [5], and it affects the residents' quality of life by causing traffic congestion and other issues [6] Of course, there are also impacts brought by welfare on other aspects of tourism, and the idea of welfare can affect the scale and scope of tourism in various ways, which may have a complex indirect effect on the innovation of tourism products and tourism services [7]. However, there are still few studies on the satisfaction of people's livelihood in tourism areas, especially the studies which focus on the satisfaction of the residents in small towns by comparing data through years.

Yangshuo, in Guangxi Province, is the famous tourism destination in Guangxi, which became well-known worldwide because of the film Liu San Jie. Boasting the unique beauty of the landscape, Yangshuo ranked in the top in "2014 the Most Beautiful County in China”, and enjoys the reputation of "Yangshuo landscape tops those in Guilin". Tourism industry is highly integrated with local economy in Yangshuo, which makes the place a typical empirical object when carrying out studies on the livelihood effect of tourism. This paper takes Yangshuo County of Guilin as an example, and analyzes the influence of the tourism development on people's livelihood by comparing the situation ten years ago with that in nowadays from the perspective of the residents' satisfaction perception, and explores the differences of satisfaction with people's livelihood of different segments, looking forward to reveal the inherent relationship between tourism development and the

Research Fund: China Postdoctoral Science Foundation Project (2016M590847), Postdoctoral Specific Fund Program of Guangxi Province, Research foundation of Guangxi University (XBS12005). 
improvement of local residents' livelihood, and to seek for an effective path to improve the satisfaction of local residents with their livelihood, so as to provide a new perspective for formulating policies in tourism industry which may bring benefits to people's livelihood.

\section{RESEARCH DESIGN AND DATA ANALYSIS}

\section{A. Questionnaire Design and Data Acquisition}

In order to investigate the changes in the local residents' satisfaction with livelihood in tourism towns of the past decade, two parts are included in the questionnaire. The first part is the survey of basic information, including the gender, age, monthly income, occupation, education, main income sources and other demographic characteristics of the respondents; in the second part, people give scores by comparing their satisfaction with specific factors in tourism industry which affect people's livelihood of the past ten years, and 12 specific factors are involved and the Likert scale is used to assign score from 1 to 5 according to the respondents' degree of satisfaction from low to high respectively, meanwhile, the data are processed with SPSS 19.0.

The questionnaires were distributed in West Street of Yangshuo County, Yulong River Scenic Area, Shanshui Theater of Impression of Liu Sanjie and other areas with a relatively large number of tourists and residents in June 2016. A total of 350 questionnaires were distributed and 336 of which were collected. The collecting rate was 96\%, and there were 294 valid questionnaires after excluding unqualified ones, accounting for $87.5 \%$ of the collected questionnaires, reaching a valid rate of $84 \%$. The basic characteristics of the survey sample are shown in Table 1.

TABLE I. TABLE 1 BASIC CHARACTERISTIC OF SURVEYED RESIDENTS IN YANGSHUO

\begin{tabular}{|c|c|c|c|c|}
\hline \multicolumn{2}{|c|}{ Demographic Characteristics } & \multirow{2}{*}{$\begin{array}{c}\text { Frequency } \\
108\end{array}$} & \multirow{2}{*}{$\begin{array}{c}\text { Percentage } \\
36.73 \\
\end{array}$} & \multirow{2}{*}{$\begin{array}{c}\text { Cumulative Percentage } \\
36.73 \\
\end{array}$} \\
\hline Gender & Male & & & \\
\hline verice & Female & 186 & 63.27 & 100.00 \\
\hline \multirow{5}{*}{ Age } & $1<18$ & 52 & 17.69 & 17.69 \\
\hline & $18-29$ & 104 & 35.37 & 53.06 \\
\hline & $30-45$ & 96 & 32.65 & 85.71 \\
\hline & $46-60$ & 32 & 10.88 & 96.60 \\
\hline & $>60$ & 10 & 3.40 & 100.00 \\
\hline \multirow{5}{*}{ Monthly Income } & $<1000(\mathrm{RMB})$ & 65 & 22.11 & 22.11 \\
\hline & $1000-2000$ & 71 & 24.15 & 46.26 \\
\hline & $2000-3500$ & 98 & 33.33 & 79.59 \\
\hline & $3500-5000$ & 39 & 13.27 & 92.86 \\
\hline & $>5000$ & 21 & 7.14 & 100.00 \\
\hline \multirow{9}{*}{ Occupation } & Student & 60 & 20.41 & 20.41 \\
\hline & Employee of SOE & 5 & 1.70 & 22.11 \\
\hline & City Servant & 5 & 1.70 & 23.81 \\
\hline & Employee of Public Institutions & 38 & 12.93 & 36.73 \\
\hline & Employee of Private Corporations & 52 & 17.69 & 54.42 \\
\hline & Farmer & 31 & 10.54 & 64.97 \\
\hline & Self-employed & 27 & 9.18 & 74.15 \\
\hline & Retiree & 37 & 12.59 & 86.73 \\
\hline & Others & 39 & 13.27 & 100.00 \\
\hline \multirow{4}{*}{ Education } & Middle School \& High School & 155 & 52.72 & 52.72 \\
\hline & Junior College \& Secondary College & 81 & 27.55 & 80.27 \\
\hline & Bachelor & 55 & 18.71 & 98.98 \\
\hline & Master and above & 3 & 1.02 & 100.00 \\
\hline \multirow{5}{*}{ Main income source of the family } & Farming & 66 & 22.45 & 22.45 \\
\hline & Factory Worker & 50 & 17.01 & 39.46 \\
\hline & Tourism Industry & 54 & 18.37 & 57.82 \\
\hline & Other Service Industry & 58 & 19.73 & 77.55 \\
\hline & Others & 66 & 22.45 & 100.00 \\
\hline
\end{tabular}


TABLE II. TIME COMPARISON OF RESIDENTS’ SATISFACTION WITH PEOPLE’S LiVELIHOOD IMPROVEMENT

\begin{tabular}{|c|c|c|c|c|c|c|}
\hline \multirow{2}{*}{ Factors } & \multicolumn{2}{|c|}{ Ten years ago } & \multicolumn{2}{|c|}{ Now } & \multicolumn{2}{|c|}{ Difference } \\
\hline & Mean(E) & $\begin{array}{l}\text { Standard } \\
\text { deviation }\end{array}$ & $\operatorname{Mean}(\mathrm{E})$ & $\begin{array}{l}\text { Standard } \\
\text { deviation }\end{array}$ & Mean(E) & $\begin{array}{l}\text { Standard } \\
\text { deviation }\end{array}$ \\
\hline Working Condition & 2.86 & 1.291 & 3.09 & 1.259 & 0.23 & -0.032 \\
\hline Income Level & 2.45 & 1.257 & 2.88 & 1.285 & 0.43 & 0.028 \\
\hline $\begin{array}{l}\text { Road Quality and Traffic } \\
\text { Condition }\end{array}$ & 2.54 & 1.257 & 2.83 & 1.357 & 0.29 & 0.1 \\
\hline $\begin{array}{c}\text { Power Supply, Water Supply, } \\
\text { Communication and Other } \\
\text { Facilities }\end{array}$ & 2.86 & 1.212 & 3.45 & 1.181 & 0.59 & -0.031 \\
\hline Price, Cost of Living & 2.72 & 1.379 & 2.37 & 1.305 & -0.35 & -0.074 \\
\hline $\begin{array}{l}\text { Living Environment, Landscape } \\
\text { and Scenery of the Town }\end{array}$ & 3.35 & 1.208 & 3.51 & 1.241 & 0.16 & 0.033 \\
\hline $\begin{array}{c}\text { Garbage Disposal, Noise Pollution } \\
\text { Control }\end{array}$ & 2.76 & 1.222 & 3.05 & 1.287 & 0.29 & 0.065 \\
\hline Education Condition & 2.88 & 1.147 & 3.24 & 1.283 & 0.36 & 0.136 \\
\hline Medical Condition and Facilities & 2.64 & 1.147 & 3.06 & 1.285 & 0.42 & 0.138 \\
\hline $\begin{array}{l}\text { Public Recreational Facilities and } \\
\text { Space }\end{array}$ & 2.65 & 1.150 & 3.10 & 1.267 & 0.45 & 0.117 \\
\hline Pension and Social Security & 2.61 & 1.166 & 3.15 & 1.232 & 0.54 & 0.066 \\
\hline Housing Condition & 2.65 & 1.230 & 3.10 & 1.324 & 0.45 & 0.094 \\
\hline Average Value & 2.75 & 1.222 & 3.07 & 1.276 & 0.31 & 0.053 \\
\hline
\end{tabular}

\section{B. Data Analysis}

\section{1) Local Residents' Satisfaction with Changes in Tourism} Livelihood

Table 2 shows that, among the satisfaction degrees with tourism livelihood in Yangshuo 10 years ago, except for the fact that the mean value of income level (2.45) was slightly lower than the median (2.50), the other 11 mean values and the average value of 12 mean values were all higher than the neutral value, indicating the fact that local residents' overall perception of tourism livelihood in the place is of positive bias, which is consistent with the overall result of Table 2. The top four of the highest average values were living environment, landscape and scenery of the town (3.35), education condition (2.88), working condition (2.86) and power supply, water supply, communication and other facilities (2.86), and the lowest three were income level (2.45), road quality and traffic condition (2.54) and pension and social security (2.61). From the standard deviation point of view, the highest one is the price, cost of living (1.379), indicating that there is a quite large gap among local residents in this aspect; the lowest one is the perception of education and medical environment (1.147), showing a relatively slight difference among the residents.

At present, the average value of residents' satisfaction with tourism livelihood in Yangshuo increases significantly with the score increased from 2.75 to 3.07, reflecting the fact that as the development of tourism industry deepens in this place, the residents are going to have a more positive attitude toward the impact on improving people's livelihood brought by the development of tourism industry. The top three of the highest are living environment, landscape and scenery of the town (3.51), power supply, water supply, communication and other facilities (3.45) and education condition (3.24), and the lowest three are price, cost of living (2.37), road quality and traffic condition (2.83), and income level (2.88). For standard deviation, the increase of the average deviation indicates the fact that with the further penetration of tourism industry, the perception difference of the improvement function of tourism among local residents further expands, which is relatively bigger in the perception of road quality and traffic condition (1.357), and smaller in power supply, water supply communication and other facilities (1.181).

By comparing the local residents' current satisfaction with tourism in improving people's livelihood with that of 10 years ago, and by calculating the deviation, the result shows that the average value of satisfaction degree improves significantly, and the top four are power supply, water supply, communication and other facilities (0.59), pension and social security (0.54), public recreational facilities and space (0.45) and housing condition (0.45); nevertheless, the residents' satisfaction in price, cost of living shows a downward trend, indicating that with the development of tourism industry, local residents enjoy the livelihood benefits brought by the improvements in living condition, infrastructure, public facilities, social welfare and other fields, but they also face some inevitable problems like rising prices and living expenses. By looking at the change in standard deviation, the fact is found that there is a decrease when it comes to the residents' difference in perception of price, cost of living, working condition, power supply, water supply, communication and other facilities, and as the tourism development deepens, the residents' difference in perception of other aspects except these three fields is increasing, which may be caused because of the local residents' different understanding of their own or the fact that how close they are related to the tourism industry, therefore, it is necessary to further understand the satisfaction among different segments in tourism areas. 
2) The Influence of Demographic Characteristics on Tourism Livelihood

Demographic characteristics like gender, age, monthly income, occupation, education and main income sources are used as basis to divide resident segments when carrying out cross analysis, and the results are shown in Table 3.

TABLE III. CROSS ANALYSIS RESUlts OF DEMOGRAPHIC CHARACTERISTICS AND SATISFACTION OF TOURISM LIVELIHOOD

\begin{tabular}{|c|c|c|c|c|c|c|}
\hline Factors & Gender & Age & $\begin{array}{l}\text { Monthly } \\
\text { Income }\end{array}$ & Occupation & Education & $\begin{array}{l}\text { Income } \\
\text { Sources }\end{array}$ \\
\hline Working Condition & .493 & $.004 * *$ & .129 & $.004^{* *}$ & .056 & $.006 * *$ \\
\hline Income Level & .675 & .142 & .115 & .064 & .353 & .600 \\
\hline Road Quality and Traffic Condition & .594 & $.002 * *$ & .416 & .077 & .120 & .068 \\
\hline $\begin{array}{l}\text { Power Supply, Water Supply, Communication and Other } \\
\text { Facilities }\end{array}$ & .079 & .086 & .129 & .381 & .300 & .117 \\
\hline Price and Cost of Living & .878 & $.000 * *$ & $.008 * *$ & $.000 * *$ & .228 & .201 \\
\hline Living Environment, Landscape and Scenery of the Town & .858 & .085 & .200 & .157 & .119 & .154 \\
\hline Garbage Disposal, Noise Control & .900 & .175 & .152 & .080 & .195 & .084 \\
\hline Education Condition & .074 & $.007 * *$ & .230 & $.006 * *$ & $.032 *$ & .059 \\
\hline Medical Condition and Facilities & .864 & $.001^{* *}$ & $.034 *$ & $.001 * *$ & $.038 *$ & $.035^{*}$ \\
\hline Public Recreational Facilities and Space & .952 & $.000^{* *}$ & .100 & $.004^{* *}$ & $.039 *$ & $.026 *$ \\
\hline Pension and Social Securities & .647 & $.006 * *$ & .087 & $.006^{* *}$ & .213 & .177 \\
\hline Housing Condition & $.037 *$ & $.000 * *$ & .214 & .059 & .138 & $.009 * *$ \\
\hline
\end{tabular}

a. Description: **,* respectively indicate significant correlation at $0.01,0.05$ level (bilateral test)

(1) There is a correlation between gender and "housing condition", and they are related with the role of men and women in the family. Data show that women are more satisfied with improvement of housing condition brought by tourism industry.

(2) Age is clearly correlated with "working condition", "road quality and traffic condition", "price and cost of living”, "education condition", "medical condition and facilities", "public recreational facilities and space”, "pension and social security", and "housing condition", and difference exists among residents of different age stages when it comes to the 8 items mentioned above, and specific manifestations are as below: residents aged below 30 or over 60 are relatively more satisfied with the improvements in working condition, education, medical condition and pension; residents aged between 30 and 60 are more concerned about the improvement of transportation, price, public recreational facilities and housing condition, and they hold a lower degree of satisfaction with the improvement, which may be related to the social environments and their own physical conditions of different age groups.

(3) Monthly income is directly correlated with "price, cost of living", "medical condition and facilities", meaning that the lower income they have, the more sensitive they are about the price and cost of living, and the less satisfied they are with the rising price caused by the development of tourism industry, but they still have a higher degree of satisfaction than people with higher income when it comes to the improvement of the medical condition and facilities.

(4) Occupation is signally correlated with "working condition”, "price and cost of living”, “education condition”, "medical condition and facilities", "public recreational facilities and space", and "pension and social security", and the residents have different perceptions of different aspects based on their occupations. For example, students have a strong sense of changes in education conditions, others are fundamentally neutral; civil servants are more aware of changes in public facilities than other groups; people of other occupations are more concerned about prices and working conditions.

(5) Education is more correlated with "education condition", "medical condition and facilities", "public recreational facilities and space". The higher degree of education they are of, the more satisfied they are with the changes.

(6) There is a significant correlation between main income sources with "working condition" and "housing condition", and a relatively strong correlation with "medical condition and facilities", and "public recreational facilities and space". Residents whose income mainly generated from tourism industry or those whose income are closely related with the industry have a relatively higher degree of satisfaction with the improvement of people's livelihood brought by tourism industry.

In general, the demographic characteristics of the residents in tourism area are correlated with the perception of people's livelihood, and the perceptions differ from each other in different segments. Due to the difference in the residents' gender, age, income, occupation, education and income sources, their psychological and physiological characteristics, life experience, cognitive level, living and working environments differ from each other, which gives rise to the difference in their views and perception levels of people's livelihood in tourism area. Therefore, in the process of improving people's livelihood through the development of tourism, the demands from residents featured different demographic characteristics should all be taken into account in order to implement precise policies which benefit the residents in developing tourism industry.

\section{CONCLUSION AND DISCUSSION}

Yangshuo typically represents small tourism towns in Guangxi Province, and the comparison between the data of 
nowadays with those of ten years ago supports the fact that the development of tourism industry has its meaning and value in improving people's livelihood in the area, and the overall impact brought by the development on people's livelihood shows a positive trend. Therefore, the development of the tourism industry in Yangshuo should be promoted based on the new concept of global tourism, adhere to the development method of "developing the industry, benefiting the people", and regard the tourism industry as one which "improves the people's livelihood and ensures the welfare of the residents" by giving full play to the positive role of tourism in improving people's livelihood, so as to benefit the local people.

It is noteworthy that the ten-year-comparison of the people's satisfaction with the livelihood also clearly points out some problems like rising price and rising cost of living brought by the development of tourism industry, which is particularly prominent in the research. Therefore, more attention should be paid to the overall situation in developing tourism industry, and during the process of drawing support from the comprehensive driving effect of tourism industry, more work should be done in stabilizing the price in case that it may discourage people from developing the industry in the area.

From the perspective of different groups, residents in tourism towns in Guangxi Province represented by Yangshuo have different degrees of satisfaction with the industry's impact on people's livelihood. Therefore, precise social benefiting policies can be implemented by considering the characteristics and diversified demands of different groups, moreover, people's livelihood demands from vulnerable groups should be paid active attention to and policies which are beneficial to the vulnerable groups should also be introduced to give consideration to both rights of participation and income of different groups, in order to achieve the fairness in benefiting the people with developing tourism industry at the same time.

\section{REFERENCES}

[1] Urtasun A, Gutiérrez I. Tourism Agglomeration and Its Impact on Social Welfare: An Empirical Approach to theSpanish Case[J]. Tourism Management,2006,27 (5) :90-912.

[2] Chesney M, Hazari B R. Illegal Migrants,Tourism and Welfare: A Trade Theoretic Approach[J]. Pacific Economic Review,2003,8(3) : 259-268

[3] Ratz T, Michalko G. The Contribution of Tourism to Wellbeing and Welfare: The Case of Hungary[J]. InternationalJournal of Sustainable Development,2011,14(3-4) : 332-346.

[4] Utpal K D, Amrita D. Nature Based Tourism,Seasonal Variation and Its Impact on Employment and Income:Evidencefrom Meghalaya[J]. Journal of Environmental Management and Tourism,2010,1(2) : 117132.

[5] Sheng L, Tsui Y. A General Equilibrium Approach to Tourism and Welfare: The Case of Macao[J]. Habitat International,2009,33 (4) : 419424.

[6] PerdueR R, Long P T,Kang Y S. Boomtown Tourism and R esident Quality of Life: The Marketing of Gaming to Host Community Residents[J]. Journal of Business Research,1999,44(3) : 165-177.

[7] Hjalager A. Innovation in Tourism from a Welfare State Perspective Scandinavian[J]. Scandinavian Journal of Hospitality and Tourism,2005,5(1) : 46-62. 